\title{
Gaps in IT and Library Services at Small Academic Libraries in Canada
}

\section{ABSTRACT}

Modern academic libraries are hubs of technology, yet the gap between the library and IT is an issue at several small university libraries across Canada that can inhibit innovation and lead to diminished student experience. This paper outlines results of a survey of small $(<5,000$ FTE) universities in Canada, focusing on IT and the library when it comes to organizational structure, staffing, and location. It then discusses higher level as well as smaller scale solutions to this issue.

\section{INTRODUCTION}

Modern academic libraries are hubs of technology, yet existing staffing, organizational structures, physical proximity and traditional ways of doing things in higher education have maintained a gap between the library and IT, which is an issue at several small university libraries across Canada.

Libraries today are largely online, which means managing access to resources, using online tools for reference and research, designing websites and more. The physical space in libraries is now a place to interact with new technologies, visualize data, a place for research support including open access repositories and data management, and other digital research initiatives. ${ }^{1}$ These library functions often require a staffing complement to support them with a level of specialization in information technology (IT). However, though the offerings of the library have changed drastically over the years, smaller university libraries have struggled to support the growing need for IT services.

Larger universities (over 5,000 FTE) have managed this influx of demand and usage of new technologies in libraries by having their own library IT services to manage software and technologies to support research, teaching and learning. Many also offer student and user-facing technical support with IT help desks within the library. Smaller universities (below 5,000 FTE) often do not have the resources to have their own IT department or staff and find themselves not able to help researchers with modern digital scholarship, not able to support new systems and software, and not working as closely with IT as they would like or need. Also, the IT department is generally not responsible for this kind of work, as it is outside of institutional-wide software support. This paper outlines the current status of IT and the library when it comes to organizational structure, physical location, and collaboration in small academic libraries across Canada. It then outlines strategies that can be used in smaller libraries to help bridge the gap, as well as recommendations for administrators when considering organizational changes to better serve a modern research atmosphere.

\section{CURRENT STATUS AT SMALL CANADIAN UNIVERSITIES}

The technologies behind modern library services are often complex, as libraries need to securely manage access to online resources (both on and off campus); support faculty as they research and

Jasmine Hoover (jasmine hoover@cbu.ca) is Scholarly Resources Librarian, Cape Breton University, Sydney, Nova Scotia, Canada. 
teach using new software and technologies; and support new models for publishing that include open-access repositories, data management, open education resources, and more. Library staff deal with technology issues that come up daily, with several non-IT library staff members troubleshooting and solving various issues that arise.

Library users run into all kinds of technical issues and reach out for help. In Nova Scotia, our library consortium offers Live Help, an online library chat service distributed throughout eleven academic institutions in Nova Scotia. Statistics kept on type of question asked on this service from January 2010 to March 2018 show that 26 percent of the over 68,000 questions asked are technical in nature, with topics including difficulty accessing online resources, login troubles, and other technical issues. ${ }^{2}$

For this study, 18 out of the 21 universities with FTE $>1,000$ and $<5,000$ in Canada were surveyed. Excluded were universities that were "sister" institutions of larger universities which utilized the same library system and French-only-speaking universities. Twelve university libraries responded to an online survey which asked questions concerning organization and collaboration focused on IT, the library, and Educational Technology.

Results (see figure 1) show that organizational reporting structures in higher education vary when it comes to IT and the library. Fifty percent of the survey respondents reported that their IT department reports to the CEO/CFO or VP administrative, 25 percent of IT departments report to a CIO, 17 percent report to a Provost/VP academic, and 8 percent report to a VP Finance.

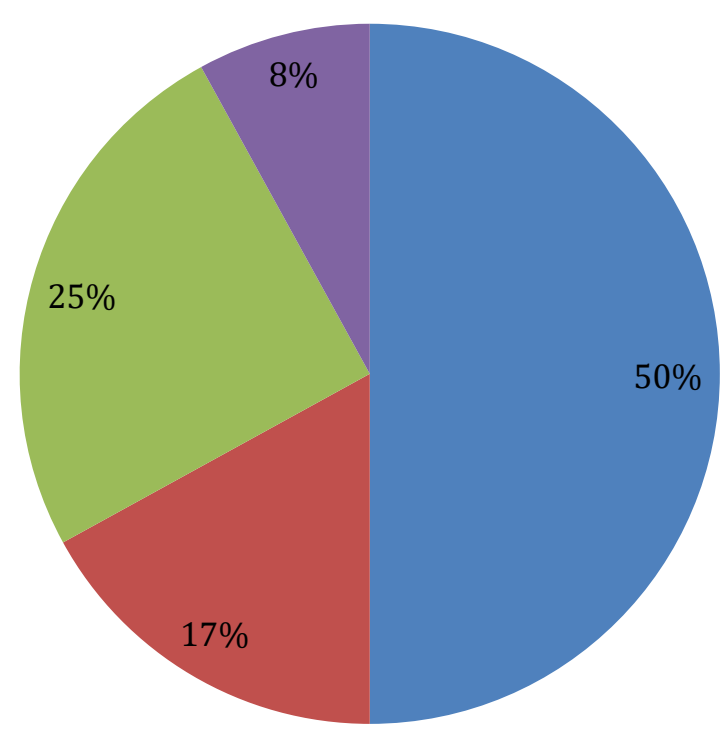

- Reports to CEO/CFO/VP admin

- Reports to Provost/ VP academic

Reports to $\mathrm{CIO}$

Reports to the VP Finance

Figure 1. Which of the following best describes how your IT organization reports?

All of the libraries in this survey, on the other hand, report to a Provost or VP Academic. This makes sense, as libraries are generally considered academic while IT is usually associated with operations. However, there have been recent changes to some university library structures in Canada that might indicate new thinking when it comes to organizational structure and the relationship between these units. In 2018, it was announced that there would be restructuring at Brandon University which removed the University Librarian position altogether (as well as the 
director of IT services), and placed the library under a Chief Information Officer. This would bring the library and IT under one reporting structure. ${ }^{3}$ In an opposite move, Mount Allison University recently proposed to eliminate the top librarian position and have an academic dean split the responsibility of the library and their academic unit. ${ }^{4}$ After local outcry, this move was reversed and the job ad is out for a head librarian. It is hard to say if these are signals of upcoming change in the future of library reporting, or a temporary solution in a time of budget restrictions. However, half of the survey respondents mentioned that there has been some recent reorganization or planned reorganization related to IT and the library at their institutions.

Only 33 percent of small university libraries surveyed have their own IT department or staff. One of those libraries have an IT specialist who splits time between the library and their IT department. The other 67 percent have no IT department or staff in the library (see figure 2).

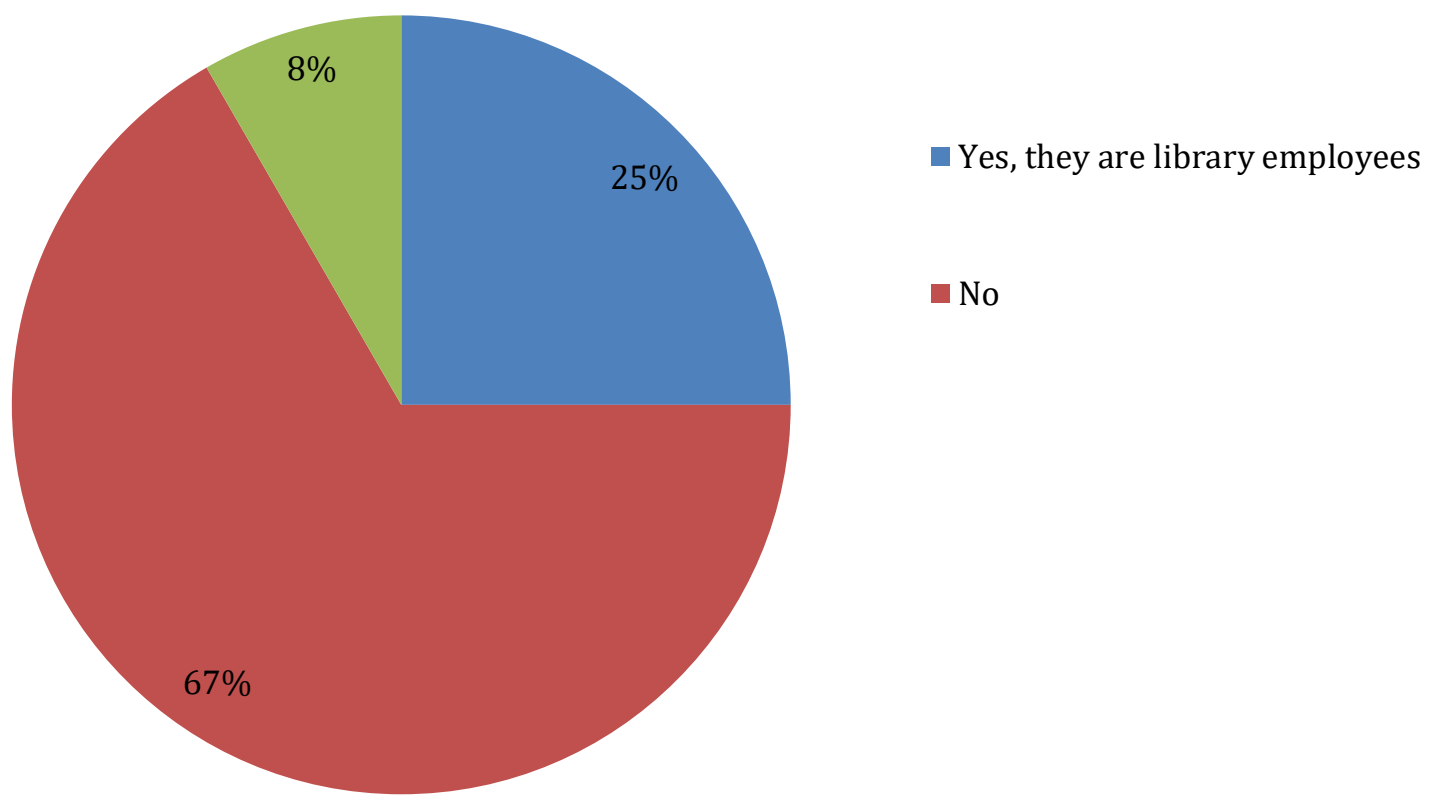

Figure 2. Does your library have its own IT department?

When asked, "Is there anything you would like changed about the current organization when it comes to IT and the library?," all of the libraries without in-library IT support mentioned a desire for either a position in the library responsible for IT; greater collaboration between IT and the library; or a specific person within the IT department who they could contact regarding IT.

Student experience, including their experience with technology is important according to a recent EDUCAUSE study. This 2017 EDUCAUSE study outlines the importance of IT, and support for students when it comes to Wi-Fi and other technical support. ${ }^{5}$ One recommendation from this report is to have IT help desks more visible and available. Not only is the library a convenient location, but as we have already seen, students are increasingly using technologies in the library and often run into issues. It makes sense then to have an IT help desk within the library, as the majority of larger university libraries in Canada already offer. When asked about IT help desks in INFORMATION TECHNOLOGY AND LIBRARIES | DECEMBER 2018 
the library, three of the responding university libraries (25 percent) have help desks staffed by IT services, one ( 8 percent) had a help desk staffed by library staff, and another ( 8 percent) had an after-hours help desk staffed by IT services. The remaining 59 percent have no IT help available in the library (see figure 3).

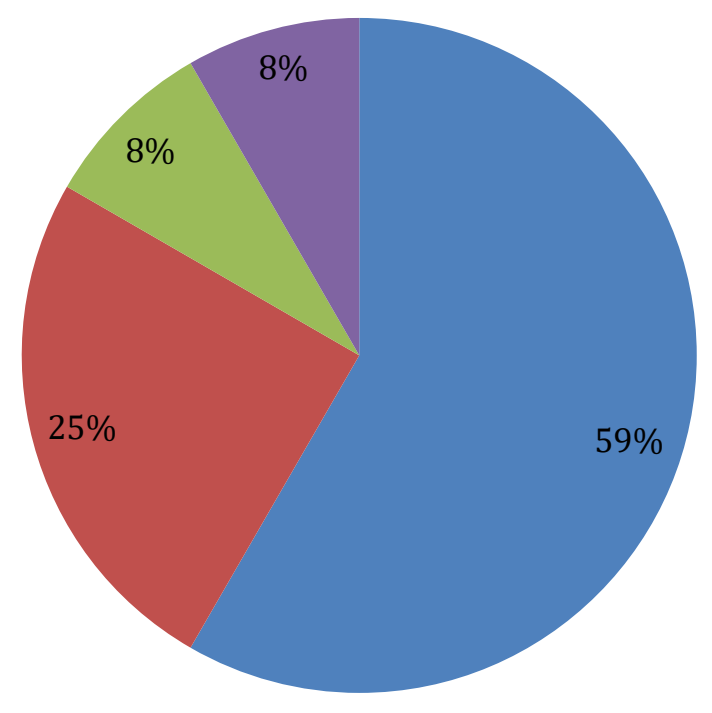

No

— Yes, employed by IT services

$\square$ Yes, employed by the library

- Yes, employed by IT services, only after hours

Figure 3. Does your library have an IT help desk?

The physical location of the two units is also important. In this survey, 75 percent of respondents replied that the library and the IT department are in separate spaces while 25 percent share a common space. Studies have shown that physical proximity in the workplace can lead to greater collaboration. An MIT study showed that physical proximity drives collaboration between researchers on university campuses. ${ }^{6}$ As one of the common themes in the survey was the desire for more collaboration, a physical change of location could have a great impact.

When asked about changes people would like to see with the current organization of the IT and library, many mention a need for more collaboration due to interrelated responsibilities. Common suggestions included library IT staff, having an IT help desk in the library, or a specific person in IT they could contact directly for help or who had shared responsibilities between IT and the library. Another suggestion was a committee that would bring together members from both units to strengthen communication.

\section{WHAT CAN BE DONE?}

In the larger view, university administrations need to look for outdated governance and organizational structures that are in place. As universities shift their goals and focus over time, they need to adapt structures and staffing accordingly. Chong and Tan describe IT governance as being of utmost importance, claiming there needs to be strategic alignment between IT and organizational strategies and objectives. ${ }^{7}$ Carraway describes universities with a high level of IT governance maturity and effectiveness as those where "IT initiatives are aligned with the 
institution's strategic priorities and prioritized among the university's portfolio projects." 8 Effective IT governance, focused on collaboration and communication, is associated with greater integration of innovation into institutional process. Also, IT governance was found to be more effective under a delegated model that empowers IT governance bodies than under a CIO centric model. The majority of universities surveyed showed common governance structures of IT, with most as separate units reporting to a CFO/VP admin or similar. The inclusion of faculty, students, and business units in IT governance committees was associated with a stronger innovation culture. ${ }^{9}$ Stakeholder inclusion is an important characteristic of IT governance maturity. Students, as consumers of IT, and faculty should both have a seat at the table when it comes to IT governance. Carraway found that an increased level of student engagement in IT governance correlates with a high level of innovation culture. ${ }^{10}$ University administration should take a good look at how IT is governed, who has input and how it is affecting the university's objectives.

The reporting structure of libraries has generally gone unchanged, with most respondents confirming that their library reports to an academic vice president. Budget constraints at two Canadian universities have seen the library structure being impacted as of late, however there has been little research done on the ideal governance structure of libraries in higher education. Both IT and the library in smaller Canadian universities could consider governance committees that include students, faculty and other stakeholders, in order to be more innovative and effective.

IT is an interesting unit, where the model in higher education has moved back and forth between three main structures: centralized, decentralized, and federated IT structures. Centralized, where there is a central hub that runs IT services for the university, is the most common structure found at the surveyed universities. Decentralized, where IT services are spread throughout the organization, would automatically mean the library (and other units) had IT staff. A federated model would also lead to local library IT work being done by specific people, who work for and out of a central IT office, but are assigned to specific areas. Federated structures offer centralized control, with decentralized functions in faculties and units. Chong and Tan believe that federated structures are more appropriate for a collaborative network, such as a university. ${ }^{11}$ Their study found that federated structure, combined with coordinated communication, led to higher effectiveness. Nugroho maintains that decentralized organizations such as universities need to regularly review their IT governance structure, as both technology and the organization itself changes. ${ }^{12}$ He maintains that effective governance does not happen by coincidence, and IT governance is not a static concept.

Library staffing also needs to change based on needs of the users and goals of the organization. Some even suggest that libraries reorganize every few years to keep staff flexible, take advantage of new opportunities and foster growth. ${ }^{13}$ In 2011, we saw Bell and Shank's work on the blended librarian, which advocated for librarianship with educational technology and instructional design skills. ${ }^{14}$ According to the 2015 ARL statistics, we continue to see nontraditional professional jobs increasing in the library. In 2015, the top three new hire categories included two nontraditional categories: digital specialists and functional specialists. ${ }^{15}$ ARCL statistics from 2016 showed that over the previous five years, 61 percent of libraries repurposed or cross-trained staff to better support new technologies or services. ${ }^{16}$ We saw in the survey that out of over 68,000 research questions fielded by librarians across Nova Scotia since 2010, just over one quarter of these are technical in nature. Library Administration at smaller universities, looking at these numbers, 
should respond by ensuring that technical knowledge and skills will be written into job ads, as they are increasingly in demand or that staff are trained appropriately.

Physical location is also important. We've seen from the survey results that there is a lack of physical connectedness between the library and IT in smaller Canadian universities. Wineman et al. studied various organizations and their physical proximity. They state: "Social networks play important roles in structuring communication, collaboration, access to knowledge and knowledge transformation." ${ }^{17}$ They suggest that innovation is a process that occurs at the crossroad between social and physical space. Cramton points out that "maintaining mutual knowledge is a central problem of geographically dispersed collaboration." ${ }^{18}$ If it is not possible to change the organizational structure or governance to ensure more communication and knowledge sharing, physical spaces such as an IT desk in the library is another way for the library and IT staff to be in regular contact. A 2017 MIT study recommended that institutions keen to support the crossdisciplinary collaborative activity that is vital to research and practice, may need to adopt "a new approach to socio-spatial organisation that may ultimately enrich the design and operation of places for knowledge creation." ${ }^{19}$ We could apply the same thinking to institutions interested in supporting collaborative activity between the library, IT, and newer-yet-related initiatives such as educational technology and digital research centers. Proximity to collaborators should be considered as one option to enhance outcomes and innovation between the library and IT.

Organizational structures and models, physical locations, and governance are all large-scale factors that should be considered when looking at the relationship between IT and the library. There are also smaller-scale practical ideas that can help. These ideas will be discussed below.

An important first step is to start the conversation. The author's institution has begun thinking about the gaps in our services and support for research, especially when it comes to support for technologies needed for modern research and publication that are often housed in the library. Factors which have helped start this conversation include: funding mandates related to open access and data management; new services or initiatives that researchers or units would like to start; which require IT and library specialization; and planning for a future in higher education that increasingly relies on up to date technologies to support research, publishing, and teaching. A conversation is beginning between researchers, administration, the library, and other stakeholders which will lead to a collaborative solution to some of these issues. It's important that there is interest and initiation from administration, but also that other stakeholders are involved from the onset. Many universities have developed new positions, new units, or worked these positions into IT or the library to fill this gap, but the solution needs to fit each institution and their goals.

Often times when there is no IT staff in the library, technical issues are managed by one or two technical-minded staff members. Equipping frontline service providers may help alleviate some of this work by enabling many staff to solve common technical issues. Here at the author's institution, the librarian in charge of access has begun presenting common technical/access issues during a monthly reference meeting. The goal is to have all staff who field questions from users have a basic understanding of how the systems work in the library, what to do if they see issues, and whom they can contact. In libraries where there is not a strong IT presence, it is important to enable staff to be comfortable with basic issues that will come up. This also ensures that there is not just one person who can answer common technical/access issues. If someone staffing the 
reference or circulation desk encounters users with these issues, they can explain why they are happening and what the library is going to do to help them. The plan is to create a library technical manual out of these quick presentations that can act as a resource for all staff or as a training manual for new staff. At each of these presentations, a survey is administered. The survey has four questions and asks participants about their comfort level dealing with technical/access questions both before and after the presentation. One hundred percent of staff answered that after the presentation, they felt more comfortable when encountering the issues described. This is not a suitable replacement of the specialized IT skills needed in libraries; however, it can alleviate some of the pressure put on select people in smaller academic libraries.

Library staff can, and do, actively work to learn new skills through formal training and professional development. We saw from the ACRL survey that many libraries are working to cross-train staff in order to keep up with technological demands. Encouraging learning new skills and educational opportunities can go a long way and should be encouraged by library administration.

The benefit of having IT staff dedicated to the library is obvious, and libraries should continually push for this. Results of the survey showed that library staff would prefer to have a person to contact with issues specific to the library. Issues can be dealt with promptly, IT personnel working in or assigned to the library will have an understanding of the systems involved, communication is easier, as there is a point person to contact, and the library has control over the products and services they offer. However, if that is not possible within the organization, a good system of communication is important. A timely system of contacting IT and resolving issues can go a long way. Chong and Tan maintain that a coordinated communication system is key for IT in an organization. ${ }^{20} \mathrm{~A}$ commonly used system for technical issues is the ticket system, where issues can be submitted by users, and answered and tracked by IT. This is a very useful system for IT staff, however the users often cannot track their own ticket, see a timeline for completion, or know who is on the other end to contact with more information. It is a good idea to meet regularly with IT, formally or informally, to be able to discuss issues, build a relationship with colleagues, and get a better sense of how each unit works. On the library end, it is important to keep statistics on technical issues sent to IT and the time elapsed before the issues are resolved. These statistics can be used to demonstrate the need for library-specific IT staff, encourage better communication between departments, or demonstrate a problem with the current way issues are communicated. Having statistics will help libraries if and when the time comes that new positions can be created. At the author's institution we use Springshare's LibAnswers software to track all technical issues, including those sent on to IT. This software records the dates and times; important details and resolutions to technical issues; and exports useful statistics.

In smaller Canadian university libraries there is a growing need for IT support. However, there has been little done by way of organizational structure, staffing, or physical proximity between these two units to allow universities to better serve their students and faculty. This paper outlined the current situation in several smaller university libraries in Canada and provides some high level as well as local solutions to this problem. 


\section{APPENDIX A: IT, LIBRARY, AND EDUCATIONAL TECHNOLOGY ORGANIZATION}

${ }^{*}$ Required

1. Institution Name*

2. Total Student Population

3. Which of the following best describes how your IT organization reports?

Mark only one oval.

Reports to CEO/CFO/VP admin

Reports to $\mathrm{CIO}$

Reports to Provost/VP Academic

Reports to Dean of Library/ Head of Library

Other:

4. Which of the following best describes how the Dean/Head of Library/University Librarian reports? Mark only one oval.

Reports to the CEO/CFO/VP admin

Reports to Provost/VP Academic

Reports to University President

Other:

5. Which of the following best describes IT's relationship to the library? Mark only one oval.

IT and the library are not at all part of the same reporting structure

$\mathrm{IT}$ is a part of the library reporting structure

IT and the library report to the same person, but are separate departments

Other:

6. Which of the following describes the physical location of IT and the library?

Mark only one oval.

Located in separate spaces

$\bigcirc$ Share a physical location

$\longrightarrow$ Other:

7. Does your library have its own IT department?

Mark only one oval.

Yes, they are library employees

Yes, they are employed by IT services and work in the library 
No

Other:

8. Does your library have an IT help desk?

Mark only one oval.

Yes, they are library employees

Yes, they are employed by IT services

No

Other:

9. Have there been any major reorganizations (that you are aware of) related to IT and library services in the last ten years?

10.Is there anything you would like changed about your current organization when it comes to IT and the library?

11.Who is in charge of Educational Technology/Academic Technology at your university?

Mark only one oval.

Library IT

Educational Technology is separate unit/office

Educational Technology duties are split up among the library/IT/other

Other:

12. Which of the following describes the physical location of Educational Technology? Mark only one oval.

Ed Tech is located in or shares space with the library

Ed Tech is located in or shares space with IT

Ed Tech has its own space

No Ed Tech unit 
Other:

13. What would you include as roles of an Educational Technology unit?

Mark all that apply.

Media design/production

Research and development (testing technologies, emerging tech)

Instructional design and development

Faculty development

Learning spaces

Assessment (learning outcomes, course evaluations)

Distance/online learning support

Training on course software/technologies related to teaching and learning

Managing classroom technologies

Other:

14. Have there been any changes (that you know of) related to Educational Technology Services in the last ten years?

15. Is there anything you would like changed about your current organization when it comes to Educational Technology Services and the library?

16. May I use direct quotes in my research/publication? (No names or institutions will be attributed to a quote.)

Mark only one oval.

Yes

No 


\section{REFERENCES}

${ }^{1}$ Tibor Koltay, “Are You Ready? Tasks and Roles for Academic Libraries in Supporting Research 2.0," New Library World 117, no. 1/2 (January 11, 2016): 94-104, https://doi.org/10.1108/NLW-09-2015-0062.

2 “Instant Messaging Service-Statistics Data Entry Page," Novanet, accessed June 5, 2018, https://util.library.dal.ca/livehelp/liveh3lp/admin/livehelp/chatentry.php.

3 “Brandon University Will Eliminate $15 \%$ of Senior Administration to Help Tackle Budget Cut," Brandon University, March 15, 2018, https://www.brandonu.ca/news/2018/03/15/brandonuniversity-will-eliminate-15-of-senior-administration-to-help-tackle-budget-cut/.

${ }^{4}$ Joseph Tunney, "Mount A Proposal to Phase out Top Librarian Makes Students, Staff Want to Make Noise," CBC News, January 18, 2018, https://www.cbc.ca/news/canada/newbrunswick/mount-allison-university-librarian-1.4492297.

${ }^{5}$ D. Christopher Brooks and Jeffrey Pomerantz, "ECAR Study of Undergraduate Students and Information Technology," EDUCAUSE, October 18, 2017, accessed June 7, 2017, https://library.educause.edu/resources/2017/10/ecar-study-of-undergraduate-studentsand-information-technology-2017.

${ }^{6}$ Matthew Claudel et al., "An Exploration of Collaborative Scientific Production at MIT through Spatial Organization and Institutional Affiliation," PLOS ONE 12, no. 6 (2017), https://doi.org/10.1371/journal.pone.0179334.

${ }^{7}$ Josephine Chong and Felix B. Tan, "IT Governance in Collaborative Networks: A Socio-Technical Perspective," Pacific Asia Journal of the Association for Information Systems 4, no. 2 (2012).

${ }^{8}$ Deborah Louise Carraway, "Information Technology Governance Maturity and Technology Innovation in Higher Education: Factors in Effectiveness" (master's diss., The University of North Carolina at Greensboro, 2015), 113.

${ }^{9}$ Ibid., 89.

10 Ibid.

${ }^{11}$ Chong and Tan, “IT Governance in Collaborative Networks: A Socio-Technical Perspective,” 44.

${ }^{12}$ Heru Nugroho, "Conceptual Model of IT Governance for Higher Education Based on Cobit 5 Framework," Journal of Theoretical and Applied Information Technology, 60, no. 2 (February 2014): 6.

${ }^{13}$ Gillian S. Gremmels, "Staffing Trends in College and University Libraries," Reference Services Review 41, no. 2 (2013): 233-52, https://doi.org/10.1108/00907321311326165.

14 John D. Shank and Steven Bell, "Blended Librarianship.” Reference \& User Services Quarterly 51, no. 2 (Winter 2011): 105-10. 
${ }^{15}$ Stanley Wilder, "Hiring and Staffing Trends in ARL Libraries," Association of Research Libraries, October 2017, https://www.arl.org/storage/documents/publications/rli-2017-stanleywilder-article2.pdf.

16 "New ACRL Publication: 2016 Academic Library Trends and Statistics," News and Press Center, July 20, 2017, http://www.ala.org/news/member-news/2017/07/new-acrl-publication-2016academic-library-trends-and-statistics.

17 Jean Wineman et al., "Spatial Layout, Social Structure, and Innovation in Organizations," Environment and Planning B: Planning and Design 41, no. 6 (December 1, 2014): 1,100-112, https://doi.org/10.1068/b130074p.

${ }^{18}$ Catherine Durnell Cramton, "The Mutual Knowledge Problem and Its Consequences for Dispersed Collaboration,” Organization Science 12, no. 3 (May-June2001): 346-71, https://doi.org/10.1287/orsc.12.3.346.10098.

${ }^{19}$ Claudel et al., "An Exploration of Collaborative Scientific Production at MIT through Spatial Organization and Institutional Affiliation," 2.

${ }^{20}$ Chong and Tan, "IT Governance in Collaborative Networks: A Socio-Technical Perspective," 44. 